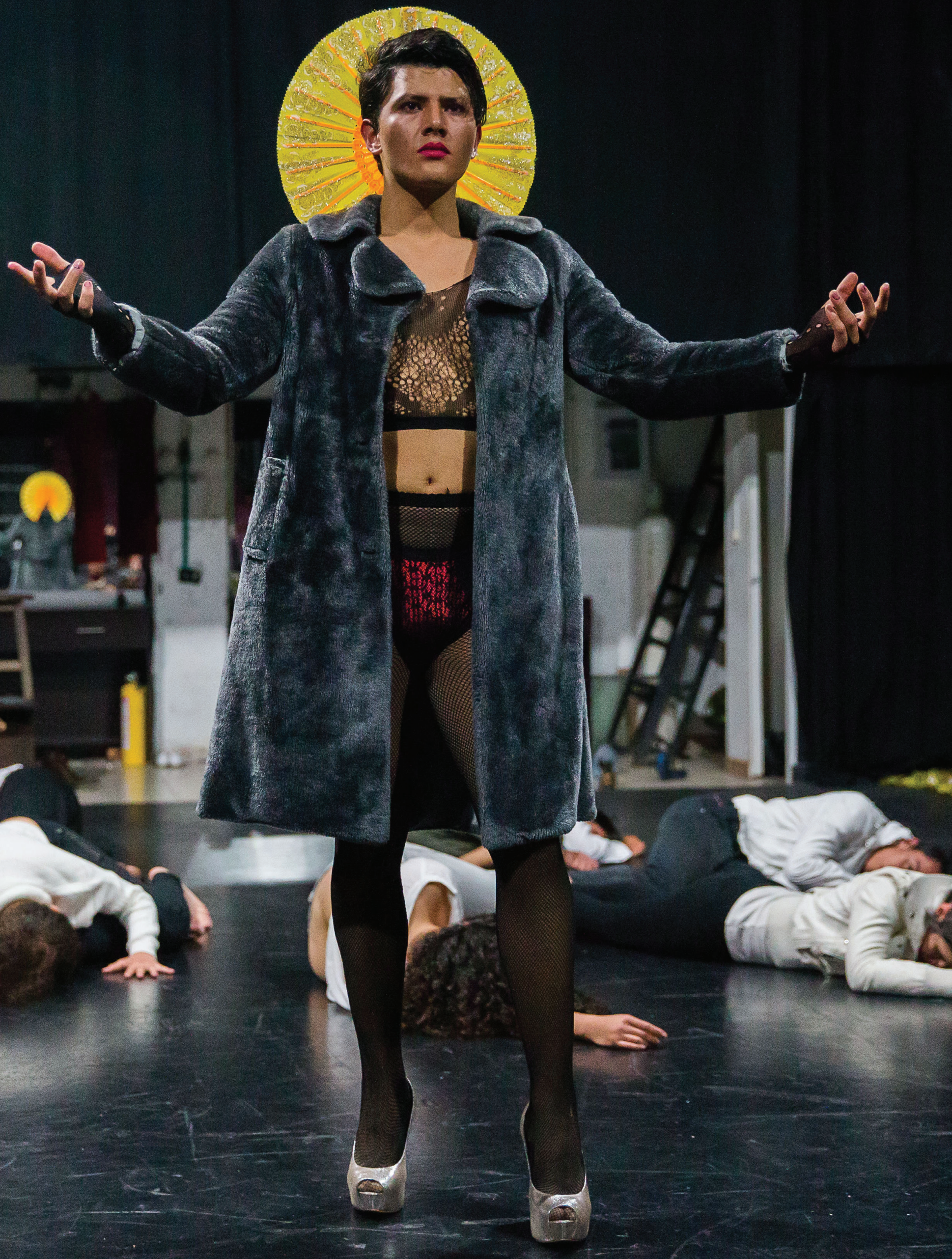




\section{Para decolonizar las geopolíticas del sentir}

\author{
Pedro Pablo Gómez Moreno \\ Editor \\ Universidad Distrital Francisco José de Caldas, \\ Colombia \\ ppgomezm@udistrital.edu.co
}

Cómo citar este artículo: Gómez Moreno, Pedro Pablo (2019). Para decolonizar las geopolíticas del sentir. Estudios Artísticos: revista de investigación creadora, 5(7) pp. 154-159. DOI: https://doi. org/10.14483/25009311.14984

Yo soy Bukowski el anormal. Director, Dubian Gallego. Fotografía: Carlos Mario Lema (2018).

\section{(c) (i)}

https://creativecommons.org/licenses/by/4.0/deed.es
Intentemos relacionar la colonialidad del espacio y del tiempo con la geopolítica del conocimiento y la geopolítica del sentir. En 1977 en su Filosofía de la liberación, Enrique Dussel, hizo evidente su conciente geopolítico, al hablar del espacio como campo de batalla, social, política y epistémica (Dussel, 1996). En términos geopolíticos entonces, no es lo mismo nacer en el Polo Norte, en Chiapas o en Bolivia que, en Nueva York, pues hay un muro de diferencia colonial construido durante 500 años de modernidad. La gepolítica del conocimiento es la espacialización epistemológica del saber, y así como la economía produce centros y periferias, la epistemología también lo hace. En el Norte geográfico hay sures epistémicos así como en el Sur geográfico hay nortes epistémicos.

Ahora bien, si en términos geográficos, Colombia está distante de Francia o de Grecia, en términos de geopolítica del conocimiento está cerca, en tanto que está más lejos del Tawantinsuyo o de Anáhuac, aunque esté próxima geográficamente. Algo similar ocurre con la estética y el arte; en términos de geopolítica del sentir el arte colombiano y el arte latinoamericano están más cerca del arte de Europa y Estados Unidos que del arte pre-hispánico portugués, al cual por supuesto no se considera arte en los mismos términos. Esa proximidad cultural es el resultado de la voluntad de acercamiento de los Estados, las instituciones y los artistas de la perifera a la cultura de los Estados del centro, desde donde se trazan los términos de la espacialización. Y cuando pareciera que la distancia epistémica y estética se puede abolir completamente, que es posible para la periferia acceder a la cultura, al desarrollo, a la historia del arte o al progreso, entonces se hace visible el muro de diferencia colonial o imperial. Así como el joven Kant, realizó una geoestética del sentir clasificando el sentimiento de lo bello $y$ lo sublime entre los países, el término mismo de 
historia del arte latinoamericano hace visible el muro de diferencia geo-estética y geo-histórica que se alza con respecto al gran arte europeo, considerado simplemente arte universal. Una concepción distinta de espacio se aplica en cada caso, el arte europeo goza de una concepción abstracta, idealizada y vacía del espacio, razón por la cual puede dar el salto de lo particular a lo universal y, en consecuencia, ser considerado arte con " $A$ " mayúscula y universal, no obstante su localización particular y su origen provincial. El arte latinoamericano en cambio, está atravezado por un espacio jerarquizado, hecho concreto durante cinco siglos. Por esta razón, está condenado a ser local, sin las mismas posibilidades de universalización con las que cuenta el arte eropeo o norteamericano, dependiente de los euroUSA centros de la estética, la historia y el mercano. De ahí que tenga sentido la pregunta acerca de si vale la pena continuar construyendo historias del arte 0 estéticas en los mismos términos de la geo-política del sentir, o si es mejor indagar en las condiciones de posibilidad de construir historias locales, capaces de conectar las prácticas artísticas contemporáneas con las memorias propias, en un horizonte decolonial de liberación cultural, epistémica y estética.

Se trataría de historias que no tengan que pasar por el centro desde el que se proyectan y validan las geopolíticas del sentir, capaces de desencubrir otras memorias, otras prácticas y otros modos de hacer. Esas historias otras, no obstante su localidad, puedan ayudarnos a imaginar un pluriverso en el que ningún particular se proyecta como universal, cortándoles las posibilidades de flocerimiento a los demás. En Estudios Artísticos: Revista de investigación creadora, estamos convencidos de la posibilidad de creación de ese pluriverso posible y somos mediadores de todos aquellos que están en la tarea de construirlo.

\section{Referencias}

Dussel, E. D. (1996). Filosofía de la liberación. Bogotá: Nueva América.

Gómez, P. P. (2015). Estéticas Fronterizas: diferencia colonial y opción estética decolonial. Bogotá: Universidad Distrital FJDC / Universidad Andina Simón Bolívar. 